\title{
Zirconium (IV) Acetylacetonate: Ring-Opening Initiator Mediating One-Step Synthesis of Biodegradable Polyacids
}

\author{
Piotr Dobrzyński (iD, Małgorzata Pastusiak, Joanna Jaworska (iD, Bożena Kaczmarczyk, \\ Michał Kwiecień, and Michał Kawalec
}

Centre of Polymer and Carbon Materials, Polish Academy of Sciences, Zabrze 41-819, Poland

Correspondence should be addressed to Michał Kawalec; michal.kawalec@cmpw-pan.edu.pl

Received 31 October 2018; Revised 28 January 2019; Accepted 7 February 2019; Published 3 March 2019

Academic Editor: Maria L. Focarete

Copyright (C) 2019 Piotr Dobrzyński et al. This is an open access article distributed under the Creative Commons Attribution License, which permits unrestricted use, distribution, and reproduction in any medium, provided the original work is properly cited.

\begin{abstract}
Biodegradable polyacid is obtained in one-step ring-opening polymerization (ROP) of carboxylic-acid-functionalized sixmembered cyclic carbonate mediated with zirconium (IV) acetylacetonate. Exemplary copolymers with L,L-lactide are described as well. Moreover, zirconium (IV) acetylacetonate is found to be active catalyst of trimethylene carbonate (TMC) ROP in presence of carboxylic acid yielding PTMC end-capped with the acid derivative. Polymerization mechanism is hypothesized demonstrating possibilities of the method in work-saving polycation synthesis and one-step method of conjugate synthesis of well-known biocompatible polyesters and polycarbonates.
\end{abstract}

\section{Introduction}

Biodegradable functional polymers gained attention of the scientific community during recent years, especially functional aliphatic polycarbonates [1-3] or, in general, copolymers comprising functional aliphatic carbonate units. The presence of such active side groups opens the door to many new applications mostly in biomedical field $[4,5]$ which covers drug release and gene delivery [6-8] among which nanostructures formulation can be found $[9,10]$. The carbonate monomers are mostly six-membered cyclic carbonates derived either from glycerol or 2,2-bis(hydroxymethyl)propionic acid (bis-MPA) though scientific literature gives examples of many more substrates. A large number of introduced groups, e.g., alkyl, aryl, alkene, alkyne, functionalities with halogen atoms, nitrogen-containing functionalities (azide, amine, amid, carbamate, and urea), or even protected sugar functionalities are reviewed elsewhere [1, 2]. Polymers and copolymers of the carbonates were obtained via ringopening (co)polymerization of the carbonates, applying ionic, coordinative, and enzymatic catalysts as well as organocatalysis $[1,3]$. However, hitherto used ROP initiators and catalysts were not active in the presence of acidic groups and did not allow simple synthesis of polymers containing pendant carboxylic groups. Generally, syntheses of polycarbonates bearing carboxylic acid functions involved deprotection of the carboxylic function after polymerization [11-15]. In fact, the deprotection reactions were carried out with a high and a very high yield. Some reports suggest even quantitative removal of groups protecting carboxylic functionality [14]. Unfortunately, only few examples of single-step enzymatically catalyzed synthesis of polyacid via copolymerization of carboxylic-acid-functionalized carbonate were found in the literature $[16,17]$.

On the other hand, among variety of ROP coordination catalysts zirconium (IV) acetylacetonate $\left(\left[\mathrm{Zr}(\mathrm{acac})_{4}\right]\right)$ is well-known transesterification and esterification catalyst in organic chemistry. In polymer chemistry $\left[\mathrm{Zr}(\mathrm{acac})_{4}\right]$ has been shown to be the precursor of efficient ring-opening polymerization (ROP) catalyst. Except for outstanding catalytic properties, $\left[\mathrm{Zr}(\mathrm{acac})_{4}\right]$ is far less-toxic alternative of commonly used stannous octanoate [18]. It was used for synthesis of biomedical materials like (co)polymers of, e.g., L-lactide (LA) [19] or $\varepsilon$-caprolactone (CL) [20] or even their copolymers with glycolide [21, 22] and trimethylene carbonate (TMC) [20]. However, the $\left[\mathrm{Zr}(\mathrm{acac})_{4}\right]$ complex is formed by zirconium atom coordinated by four chelating 
TABLE 1: Conversion of monomers and product characterization of MTCOOH/LA/[Zr $\left.(\mathrm{acac})_{4}\right](300 / 700 / 1)$ copolymerization carried out in bulk at $120^{\circ} \mathrm{C}$.

\begin{tabular}{|c|c|c|c|c|c|c|c|}
\hline Entry & $\begin{array}{c}\text { Time } \\
{[\mathrm{h}]}\end{array}$ & $\begin{array}{c}\text { MTC-COOH } \\
\text { conversion } \\
{[\%]} \\
\end{array}$ & $\begin{array}{c}\text { LA } \\
\text { conversion } \\
{[\%]} \\
\end{array}$ & $\begin{array}{c}\text { Product } \\
\text { composition } \\
\text { MTC-COOH/LA }\end{array}$ & $\begin{array}{c}M_{\mathrm{n}} \\
\times 10^{-3} \\
{[\mathrm{~g} / \mathrm{mol}]}\end{array}$ & $\begin{array}{c}M_{\mathrm{w}} \\
\times 10^{-3} \\
{[\mathrm{~g} / \mathrm{mol}]}\end{array}$ & $Ð$ \\
\hline 1. & 2.25 & 12 & 8 & $40 / 60$ & 1.0 & 1.3 & 1.3 \\
\hline 2. & 24 & 68 & 66 & $40 / 60$ & 3.4 & 5.0 & 1.5 \\
\hline 3. & 48 & 96 & 94 & 39 / 61 & 4.2 & 8.0 & 1.9 \\
\hline $4 . *$ & - & - & - & 39 / 61 & 10 & 21 & 2.1 \\
\hline
\end{tabular}

* indicates polymer precipitated from its chloroform solution into cold diethyl ether.

$\beta$-diketonate ligands, acetylacetonates, forming eightcoordinate structure $[23,24]$. Such complex is barely sensitive towards air and moisture and tends to be inert towards various chemicals at lower temperature [25]. Importantly, the complex becomes active ROP catalyst after at least one acetylacetonate ligand release and geometry change into seven coordinates $[19,20]$. Apparently, cocatalyst (proton donor: cyclic esters or alcohol) was necessary to generate active zirconium (IV) catalyst in situ in the case of cyclic carbonate monomers polymerization [20]. Though cyclic carbonate monomer with pendant carboxyl group should be able to exchange acetylacetonate ligand and convert $\left[\mathrm{Zr}(\mathrm{acac})_{4}\right]$ into active ROP catalyst.

Hereafter, implementation of zirconium (IV) acetylacetonate in synthesis of biodegradable polyacids is described. Polymerization mechanism of 5-methyl-2-oxo-1,3-dioxane5-carboxylic acid (MTC-COOH) is hypothesized based on model polymerization of TMC in presence of benzoic acid.

\section{Materials and Methods}

2.1. Materials. Monomers, L-lactide (LA) (Glaco Ltd., China) and 1,3-trimethylene carbonate (TMC) (Huizhou Foryou Medical Devices Co., Ltd., China), were purified by recrystallization from anhydrous ethyl acetate and then dried in a vacuum oven at room temperature till constant weight. Benzoic acid $\geq 99.5 \%$ (Aldrich), zirconium (IV) acetylacetonate $\left(\mathrm{Zr}(\mathrm{acac})_{4}\right)$ (Aldrich), 2,2-bis(hydroxymethyl)propionic acid (bis-MPA) (98\%, VWR), benzyl bromide (98\%, Aldrich), ethyl chloroformate (97\%, VWR), Pd/C (Aldrich), anhydrous $\mathrm{MgSO}_{4}$ (Avantor Performance Materials, Poland), diatomaceous earth (Celite ${ }^{\circledR} 545$, Sigma-Aldrich), N,Ndimethylformamide (DMF) (99.8\%, VWR), ethyl acetate, toluene, chloroform, and diethyl ether (all: p.a., Avantor Performance Materials, Poland) were used as received. Triethylamine $\left(\mathrm{NEt}_{3}\right)$ (>99\%, Aldrich) was dried over $\mathrm{BaO}$ and distilled under reduced pressure prior to use.

2.2. Functional Carbonate Monomer Synthesis. 5-Methyl-2oxo-1,3-dioxane-5-carboxylic acid (MTC-COOH) was synthesized as described earlier [26, 27]; in detail, bis-MPA (270.000 g, $2.013 \mathrm{~mol}, 1 \mathrm{eq}$.) was dissolved in $1.3 \mathrm{dm}^{3}$ of DMF and $\mathrm{KOH}$ (135.537 g, 2.416 mol, 1.2 eq.) was added. Clear solution was obtained after the mixture was heated to $100^{\circ} \mathrm{C}$. Next, benzyl bromide $\left(287 \mathrm{~cm}^{3}, 413.134 \mathrm{~g}, 2.416\right.$ mol, 1.2 eq.) was added and the reaction was carried out overnight at $100^{\circ} \mathrm{C}$. Then, after DMF had been stripped off under reduced pressure, nonvolatiles were dissolved in 3.0 $\mathrm{dm}^{3}$ of dichloromethane and organic solution was washed 3 times with $500 \mathrm{~cm}^{3}$ (each wash) of aq. dist. followed by drying over anhydrous $\mathrm{MgSO}_{4}$. After $\mathrm{MgSO}_{4}$ had been filtered off and the solvent had been stripped off, the residual solid was recrystallized from toluene to yield white crystals of benzyl 2,2-bis(methylol) propionate which were dried under vacuum $\left(\mathrm{T}=50^{\circ} \mathrm{C}\right)$ to constant weight. Yield $=63 \%$.

Next, under nitrogen flow, into a solution composed of benzyl 2,2-bis(methylol) propionate ( $86.5 \mathrm{~g}, 0.386 \mathrm{~mol}, 1 \mathrm{eq}$. and ethyl chloroformate $\left(110 \mathrm{~cm}^{3}, 125.72 \mathrm{~g}, 1.158 \mathrm{~mol}, 3 \mathrm{eq}.\right)$ in $1500 \mathrm{~cm}^{3}$ of chloroform $\mathrm{CHCl}_{3}$, thermostated in an ice/water bath, triethylamine $\left(161 \mathrm{~cm}^{3}, 117.18 \mathrm{~g}, 1.158 \mathrm{~mol}, 3\right.$ eq.) was introduced dropwise. Then, the cooling bath was removed and reaction carried out overnight. Next, the mixture was washed with $2 \times 150 \mathrm{~cm}^{3} 1 \mathrm{M} \mathrm{HCl}_{\mathrm{aq}}, 150 \mathrm{~cm}^{3}$ saturated aqueous solution of $\mathrm{NaHCO}_{3}, 150 \mathrm{~cm}^{3}$ brine and finally 2 $\times 50 \mathrm{~cm}^{3}$ aq. dist. Organic phase was dried over anhydrous $\mathrm{MgSO}_{4}$. Next, $\mathrm{MgSO}_{4}$ was filtered off, $\mathrm{CHCl}_{3}$ stripped off and the nonvolatile residue was recrystallized from toluene to yield white crystals of benzyl 5-methyl-2-oxo-1,3-dioxane5-carboxylate (MTC-COOBn). Yield $=87 \%$.

After addition of $1.5 \mathrm{~g}$ of $\mathrm{Pd} / \mathrm{C}$ into solution of benzyl 5methyl-2-oxo-1,3-dioxane-5-carboxylate (15.0 g, $60.0 \mathrm{mmol}$ ) in $200 \mathrm{~cm}^{3}$ of ethyl acetate and hydrogen agitation for $8 \mathrm{~h}$, resulting material was dissolved in $100 \mathrm{~cm}^{3}$ of THF and filtered through diatomaceous earth. Next, the solvents were stripped off and the resulting white crystals of 5-methyl-2oxo-1,3-dioxane-5-carboxylic acid were dried under vacuum to constant weight. Yield=98\%.

\subsection{Polymerization and Copolymerization Procedures}

2.3.1. MTC-COOH/LA copolymerization (Table 1) was performed in 3-necked glass flask of $25 \mathrm{~mL}$ capacity, equipped with a magnetic stirring bar. L-lactide $(2.1 \mathrm{~g}, 14.60 \mathrm{mmol}$, 702 eq.), MTC-COOH (1.0 g, $6.24 \mathrm{mmol}, 300$ eq.), and zirconium (IV) acetylacetonate $(0.0102 \mathrm{~g}, 0.0208 \mathrm{mmol}, 1$ eq.) were charged into flame-dried glass flask. Then, the flask was degassed under vacuum for 5 minutes, refilled with dry argon and sealed. Next, the reaction vessel was immersed in an oil bath and stirred under argon at $120^{\circ} \mathrm{C}$. The aliquots were withdrawn after specific periods of time (compare Table 1) and characterized with ${ }^{1} \mathrm{H}$ NMR, ESI-MS 
TABLE 2: MTC-COOH/LA copolymers obtained in zirconium-complex-catalysed (monomers/[Zr(acac) $\left.{ }_{4}\right]$ 1000/1) bulk polymerization carried out at $130^{\circ} \mathrm{C}$.

\begin{tabular}{|c|c|c|c|c|c|c|c|}
\hline Entry & $\begin{array}{c}\text { Monomer } \\
\text { composition } \\
\text { MTC-COOH/ LA }\end{array}$ & $\begin{array}{l}\text { Time } \\
{[\mathrm{h}]}\end{array}$ & $\begin{array}{c}\text { Conversion } * \\
{[\%]}\end{array}$ & $\begin{array}{c}\text { Polymer } \\
\text { composition* } \\
\text { MTC-COOH/ LA }\end{array}$ & $\begin{array}{l}\mathrm{M}_{\mathrm{n}} * * \\
\mathrm{x} 10^{-3} \\
{[\mathrm{~g} / \mathrm{mol}]}\end{array}$ & $\begin{array}{c}\mathrm{M}_{\mathrm{w}} * * \\
\mathrm{x} 10^{-3} \\
{[\mathrm{~g} / \mathrm{mol}]} \\
\end{array}$ & $Ð * *$ \\
\hline 1. & 100:0 & 3 & 40 & 100:0 & & $\mathrm{n} / \mathrm{d} * * *$ & \\
\hline 2. & $70: 30$ & 24 & 95 & $72: 28$ & & $\mathrm{n} / \mathrm{d} * * *$ & \\
\hline 3. & $50: 50$ & 24 & 95 & $57: 43$ & 7 & 16 & 2.3 \\
\hline 4. & $30: 70$ & 24 & 95 & $31: 69$ & 12 & 25 & 2.1 \\
\hline 5. & $0: 100$ & 48 & 100 & $0: 100$ & 110 & 230 & 2.1 \\
\hline
\end{tabular}

$*$ Determined with ${ }^{1} \mathrm{H}$ NMR technique; $* *$ determined with SEC technique; $* * *$ not determined, material insoluble, or only partially soluble in $\mathrm{CHCl}_{3}$.

(if possible), and SEC techniques. The obtained product was dissolved in chloroform and precipitated dropwise in cold diethyl ether followed by drying of the precipitate in vacuum at room temperature to constant weight. The final material was investigated with NMR, SEC and FTIR techniques.

2.3.2. TMC ( $1.02 \mathrm{~g}, 10 \mathrm{mmol}, 50$ eq.) polymerization in presence of benzoic acid $(0.098 \mathrm{~g}, 0.8 \mathrm{mmol}, 4 \mathrm{eq}$.$) and$ $\mathrm{Zr}(\mathrm{acac})_{4}$ (0.0976 g, $0.2 \mathrm{mmol}, 1$ eq.) was carried out in 3-necked flask of $25 \mathrm{~mL}$ capacity equipped with magnetic stirring bar similarly to experiment described in procedure 1 . The reaction mixture was thermostated in an oil bath and stirred vigorously at $120^{\circ} \mathrm{C}$ under an argon atmosphere if possible. The aliquots were withdrawn within four hours of the reaction course and analysed with ${ }^{1} \mathrm{H}$ NMR and SEC techniques. Resulting material was dissolved in chloroform and washed with saturated aqueous solution of $\mathrm{NaHCO}_{3}$ three times, followed by three washes with $1 \mathrm{M} \mathrm{HCl}_{\mathrm{aq}}$ and distilled water to neutral $\mathrm{pH}$. Next, the organic layer was dried over anhydrous $\mathrm{MgSO}_{4}$ and filtered. Polymer was precipitated in cold diethyl ether. Obtained material was characterized using ${ }^{1} \mathrm{H}$ NMR and SEC techniques.

2.3.3. Polymerization of MTC-COOH and LA and their copolymerization (Table 2) was performed similarly to procedure 2.3.1; briefly, respective amount of the monomer(s) was charged into dry glass vial (10 mL capacity) equipped with magnetic stirring bar, followed by addition of respective mass of $\operatorname{Zr}(\mathrm{acac})_{4}$ and sealing of the reactor. Charging of the reactor vessel was carried out in dry argon atmosphere each time and $\mathrm{Zr}(\mathrm{acac})_{4}$ amount was adjusted to keep monomer(s)/initiator precursor ratio 1000:1. Next, reactors were immersed totally in an oil bath at $130^{\circ} \mathrm{C}$ and the reactions were carried out for given time. Crude polymers were analysed with ${ }^{1} \mathrm{H}$ NMR.

2.3.4. PTMC diol was synthesized as described earlier [28]; in detail, TMC (1 g, $9.8 \mathrm{mmol}, 2450$ eq.), 1,4-butanediol (0.018 g, $0.2 \mathrm{mmol}, 50$ eq.), and zinc (II) acetylacetonate hydrate (0.001 g, $0.004 \mathrm{mmol}, 1$ eq.) were charged into dried glass flask. After 10 minutes of reaction carried out in bulk at $110^{\circ} \mathrm{C}$ the reaction mixture was cooled. Resulting oligomer was characterized with SEC $\left(M_{n}=6200[\mathrm{~g} / \mathrm{mol}]\right)$ and NMR techniques.

2.3.5. End-capping of PTMC diol with benzoic acid was carried with benzoyl chloride. Briefly, PTMC diol (0.4 g,
$0.135 \mathrm{mmol}, 1$ eq.) of the oligomer was dissolved in $8 \mathrm{~mL}$ of chloroform. Next, under dry argon flow, dry triethylamine $\left(0.039 \mathrm{~cm}^{3}, 0.284 \mathrm{mmol}, 2,1 \mathrm{eq}\right.$. $)$ was added into the solution followed by addition of benzoyl chloride $\left(0.031 \mathrm{~cm}^{3}, 0.270\right.$ mmol, 2.0 eq.). After reaction had been carried out $24 \mathrm{~h}$ at room temperature the solution was washed with $3 \times 5$ $\mathrm{cm}^{3}$ of saturated aqueous solution of $\mathrm{NaHCO}_{3}, 2 \times 5 \mathrm{~cm}^{3}$ of $1 \mathrm{M} \mathrm{HCl}_{\mathrm{aq}}$ and $3 \times 5 \mathrm{~cm}^{3}$ of distilled water. Polymer was precipitated in cold diethyl ether after organic phase had been dried over anhydrous $\mathrm{MgSO}_{4}$. NMR analyses were carried out after thorough drying under vacuum at room temperature.

2.4. Synthesis of Model Mixed Carboxylic-Carbonic Anhydride. Benzoic acid (0.507 g, $0.0041 \mathrm{mmol}, 1$ eq.) was dissolved in $5 \mathrm{~cm}^{3}$ of diethyl ether. Next, dry triethylamine $\left(0.72 \mathrm{~cm}^{3}\right.$, $0.0052 \mathrm{mmol}, 1.25 \mathrm{eq}$.) was added and the solution was cooled to $0^{\circ} \mathrm{C}$. Solution of ethyl chloroformate $\left(0.46 \mathrm{~cm}^{3}, 0.0049\right.$ $\mathrm{mmol}, 1.2 \mathrm{eq}$.) in $0.6 \mathrm{~cm}^{3}$ of diethyl ether was added dropwise. Reaction was allowed to proceed next $1.5 \mathrm{~h}$ worming up to room temperature. Next, solids were filtered off and solution was washed with $3 \times 5 \mathrm{~cm}^{3}$ of saturated aqueous solution of $\mathrm{NaHCO}_{3}, 2 \times 5 \mathrm{~cm}^{3}$ of $1 \mathrm{M} \mathrm{HCl}_{\text {aq }}$ and $3 \times 5 \mathrm{~cm}^{3}$ of distilled water. Solvent was stripped of after organic layer had been dried over anhydrous $\mathrm{MgSO}_{4}$. Product was characterized with NMR techniques.

2.5. Methods. Changes in the chain microstructure as well as changes in the (co)polymers composition were monitored on the basis of ${ }^{1} \mathrm{H}$ and ${ }^{13} \mathrm{C}$ NMR spectroscopy. Spectra were recorded with Bruker Avance II Ultrashield Plus spectrometer operating at $600 \mathrm{MHz}\left({ }^{1} \mathrm{H}\right)$ and $150 \mathrm{MHz}\left({ }^{13} \mathrm{C}\right)$, using $\mathrm{CDCl}_{3}, \mathrm{C}_{6} \mathrm{D}_{6}$ or DMSO- $\mathrm{d}_{6}$ as a solvent. Spectra were obtained with 32 scans, $11 \mu$ s pulse width, and $2.65 \mathrm{~s}$ acquisition time for ${ }^{1} \mathrm{H}$ NMR. ${ }^{13} \mathrm{C}$ NMR spectra were obtained with 20,000 scans, $9.4 \mu$ s pulse width, and $0.9 \mathrm{~s}$ acquisition time. Quantitative ${ }^{13} \mathrm{C}$ spectra were recorded without NOE for selected samples using Bruker pulse program abbreviated as zgig (The decoupling mode is referred to as inverse-gated). The spectra were obtained with 61440 scans, $9.4 \mu$ s pulse width, and $0.9 \mathrm{~s}$ acquisition time.

ESI-MS $^{\mathrm{n}}$ analysis was performed using a LCQ Fleet ion trap mass spectrometer (Thermo Scientific). The polyester sample was dissolved in a chloroform/methanol system (1:1 $\mathrm{v} / \mathrm{v}$ ), and the solutions were introduced into the ESI source 
<smiles>CC1[CH+]C(=O)C(C)OC1=O</smiles><smiles>CC(C)(C)C1COC(=O)OC1</smiles><smiles>CCOC(=O)C(C)(C)C(C)(C)COC(C)C(=O)OC(C)(C)C</smiles>

SCHEME 1: L,L-Lactide (LA)/5-methyl-2-oxo-1,3-dioxane-5-carboxylic acid (MTC-COOH) copolymerization scheme.

by continuous infusion using the instrument's syringe pump at a rate of $5 \mu \mathrm{L} / \mathrm{min}$. The ESI source was operated at $4.5 \mathrm{kV}$, and the capillary heater was set to $200^{\circ} \mathrm{C}$, as the nebulising gas nitrogen was used. For ESI-MS/MS experiments, the ions of interest were isolated monoisotopically in the ion trap and were collisionally activated. The helium damping gas that was present in the mass analyser acted as a collision gas. The RF amplitude, which had a significant voltage range, was set to a value that caused the peak height of the molecular ion to decrease by at least $50 \%$. The analysis was performed in the positive-ion mode.

SEC experiments were carried out in chloroform at $35^{\circ} \mathrm{C}$ with eluent flow rate of $1 \mathrm{~mL} / \mathrm{min}$., using a set of two PLgel 5 $\mu \mathrm{m}$ MIXED-C ultrahigh efficiency columns. Isocratic pump (VE1122, Viscotek) as a solvent delivery system, UV (Spectra100, Spectra-Physics) and differential refractive index (RI SE-61, Shodex) detectors were applied. A volume of $100 \mu \mathrm{L}$ of sample solution in chloroform (concentration of $3 \% \mathrm{w} / \mathrm{v}$ ) has been injected. Number-average $\left(M_{n}\right)$, weight-average $\left(\mathrm{M}_{\mathrm{w}}\right)$ molar masses and molar mass dispersity $(\boxplus)$ values of polymers have been determined according to conventional calibration generated with polystyrene standards with narrow molar mass distribution.

FTIR spectra were recorded with JASCO FT/IR-6700 spectrometer with a resolution of $2 \mathrm{~cm}^{-1}$ and as a result of the accumulation of 64 scans. Samples in solid state were analysed using ATR equipment.

\section{Results and Discussion}

3.1. Copolymerization of Carboxylic-Acid-Functionalized Carbonate with Carboxylic Acid Group Preservation. Investigating catalytical properties of $\left[\mathrm{Zr}(\mathrm{acac})_{4}\right]$ in ring-opening polymerization it was tried to copolymerize LA with carboxylicacid-functionalized cyclic carbonate (5-methyl-2-oxo-1,3dioxane-5-carboxylic acid, MTC-COOH) (Scheme 1).

The copolymerization experiment (MTC-COOH 30 $\% \mathrm{~mol}$ and LA $70 \% \mathrm{~mol}$ ) was carried out at typical monomers/initiator ratio equal $1000 / 1$ in bulk at $120^{\circ} \mathrm{C}$ and surprisingly reached ca. $95 \%$ conversion after $48 \mathrm{~h}$. The total conversion of the monomers revealed typical trend (Figure S1) while kinetics of MTC-COOH consumption was similar to conversion of LA. In the same time increase of the molar mass occurred (Table 1).

Apparently, composition of the polymerization product was slightly different from the initial composition of the monomers (39/61 versus 30/70, respectively); however the phenomenon is explained by well-known LA sublimation which occurred during 48h-long course of the polymerization, thus constituting issue out of the chemical significance. Importantly, ${ }^{1} \mathrm{H}$ NMR analysis of the purified polymer revealed relatively broad signal at $\delta=13 \mathrm{ppm}$ as well as expected signals ascribed to respective protons of the copolymer (Figure S2) while invers-gated ${ }^{13} \mathrm{C}$ NMR analysis of the product revealed signals ascribed to copolymer carbons and pendant carboxylic group (Figure 1(a); see Figure S3 for full range ${ }^{13} \mathrm{C}$ NMR spectrum). Noticingly, carbonyl carbon signals at $\delta=169 \mathrm{ppm}$ and $173 \mathrm{ppm}$ (Figure 1(b), middle) form multiplets which usually (i) prove copolymerization of the units and (ii) suggest triads of repeating units possessing different composition.

Moreover, the NMR analyses gave a clue of preserved carboxylic functions during the polymerization course (broad signal at $\delta=13 \mathrm{ppm}$ in ${ }^{1} \mathrm{H}$ NMR spectrum (Figure S2)); however unambiguous ascription of signal at $\delta=173 \mathrm{ppm}$ was done based on comparison with ${ }^{13} \mathrm{C}$ NMR spectra of (i) LA/MTC-COOBn (5-methyl-2-oxo-1,3-dioxane-5carboxylic acid benzyl ester) copolymer (Figure 1(b), top spectrum) which revealed carbonyl carbon of the benzyl ester at $\delta=171.5 \mathrm{ppm}$ and (ii) vanishing of the signal at $\delta=173 \mathrm{ppm}$ after reaction with trichloroacetyl isocyanate (Figure 1(b), bottom). Qualitative analysis of the synthesized copolymer spectrum depicted in Figure 1(a) correlates with ${ }^{1} \mathrm{H}$ NMR analysis. Furthermore, FTIR analysis of the purified product in comparison with MTC-COOH monomer also confirmed preservation of the pendant carboxylic groups during the copolymerization reaction (Figure S4), although most of the hydrogen bonds were broken. The observed effect of weakened hydrogen bonding correlates with observations during dilution of acids. The band at $1628 \mathrm{~cm}^{-1}$ was preserved due to the fact that intramolecular hydrogen bonds were not broken quantitatively while diluting with lactide units. Further proof of carboxylic functions preservation during the polymerization process was obtained by ESI-MS analysis of reacting mixture sample (withdrawn after $2.25 \mathrm{~h}$ of polymerization experiment at conversion ca. 10\%; Table 1. Entry 1).

The experiment indicates unique properties of $\left[\mathrm{Zr}(\mathrm{acac})_{4}\right]$ as a catalyst which is able to mediate ROP of oxacyclic monomers in presence of carboxylic acids. Moreover, it was possible to synthesize polyacid in one step. Apparently, molar mass of the product was much lower than expected if initiator/monomer ratio had been 


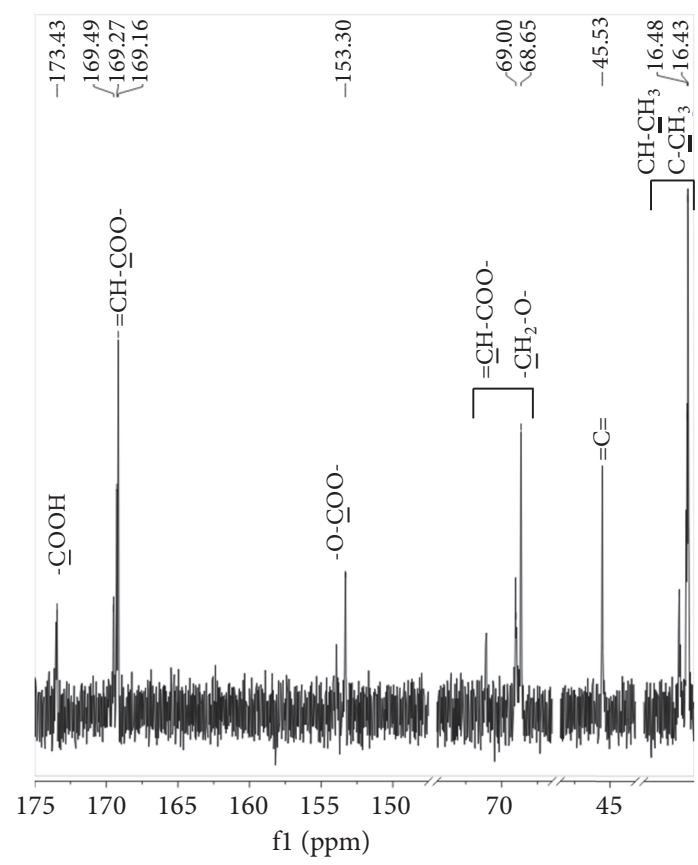

(a)

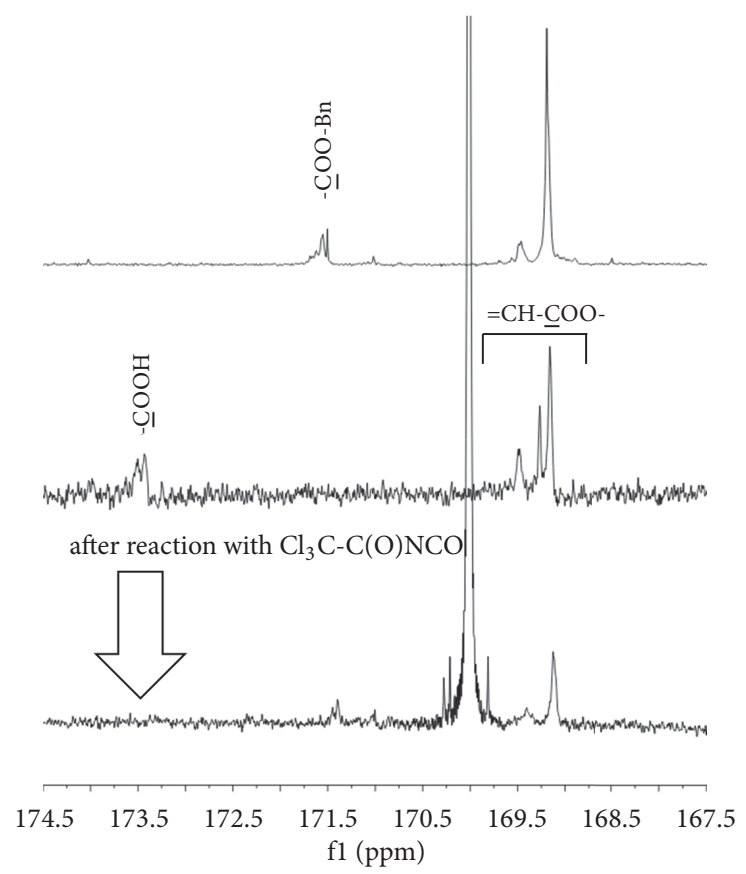

(b)

FIGURE 1: ${ }^{13} \mathrm{C}$ NMR $\left(125 \mathrm{MHz}\right.$, DMSO-d $\mathrm{d}_{6}$ ) spectra; (a) inverse-gated of MTC-COOH/LA copolymer in chosen regions; (b) its overlay with MTC-COOBn/LA copolymer (top) and MTC-COOH/LA copolymer after reaction with trichloroacetyl isocyanate (bottom).

considered. This phenomenon triggered us to carry out model experiment.

3.2. TMC Homopolymerization Mediated with $\left[\mathrm{Zr}(\mathrm{acac})_{4}\right]$ in Presence of Carboxylic Acid. Initiation of cyclic carbonate and lactide copolymerization mediated by zirconium complex is said to involve conversion of the complex in situ into heptacoordinate species after transfer of a labile acidic proton from ester (LA or CL) to ligand and release of at least one acetylacetone followed by coordination of the cyclic ester via carbonyl oxygen to the zirconium atom with formation of labile adduct $[19,20]$. In fact, proton transfer to acetylacetonate ligand is one of the two rate-determining steps in reactions of $\left[\mathrm{Zr}(\mathrm{acac})_{4}\right]$ with either acetylacetone [29] or catechols [25]. In case no proton transfer was possible to acetylacetone ligand $\left[\mathrm{Zr}(\mathrm{acac})_{4}\right]$ was not active in polymerization $[20,30]$. On the other hand acetylacetonates of bivalent metals are known to replace their ligands in presence of benzoic acid (BA) [31]. The ligand exchange was observed even in case of mixed complexes formed between the catalyst and ethylene glycol. Herein, it is hypothesized that at least one of the original acetylacetone ligands is exchanged with carboxylate group (R-COO) with removal of acetylacetone $(\mathrm{acacH})$ molecule.

The hypothesis was verified by model polymerization of TMC in presence of the $\left[\mathrm{Zr}(\mathrm{acac})_{4}\right]$ complex and benzoic acid ([Zr(acac) $\left.)_{4}\right] / \mathrm{BA} / \mathrm{TMC}$ equal: $\left.1 / 4 / 50\right)$ carried out in bulk at $120^{\circ} \mathrm{C}$. Analysis of an aliquot withdrawn after $4 \mathrm{~h}$ of reaction surprisingly revealed 95\% conversion of TMC into PTMC.

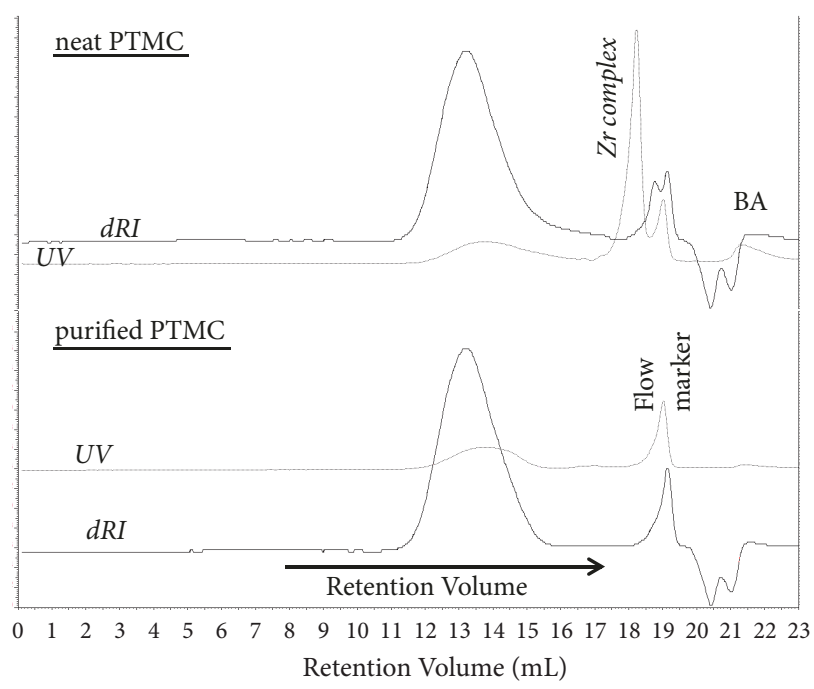

FIGURE 2: SEC elugram of PTMC obtained in presence of $\left[\mathrm{Zr}(\mathrm{acac})_{4}\right]$ and BA; neat (top) and purified (bottom).

Noticingly, three multiplets characteristic for benzoic acid protons at $\delta=7.4-8.0 \mathrm{ppm}$ were duplicated by signals of the same shape but lower intensity (Figure S6a). In the same time SEC analysis, using dRI and UV (290 nm) detectors, of the reacting mixture revealed overlapping of the UV detector response with the dRI signal (Figure 2). 
Flow marker (toluene) was observed at retention volume ca. $19 \mathrm{~mL}$ while intensive signal observed with the UV detector at retention volume $17-18.5 \mathrm{~mL}$ was attributed to zirconium complex. However, the most important is signal registered at lower retention volume $(11-17 \mathrm{~mL})$ overlapping response of the dRI detector. This region is attributed to the polymer fraction while UV detector indicates that benzoic acid derivative is incorporated in polymer chain. Repetition of the SEC analysis after thorough purification of the obtained material revealed removal of the zirconium complex as well as the partial removal of low-molar-mass polymer fraction. However, response of the UV detector at elution volume ascribed to the polymer fraction remained confirming existence of the benzoic acid derivative bounded to macromolecules. Complementary ${ }^{1} \mathrm{H}$ NMR analysis of the purified material revealed signals typical for PTMC as well as signals typical for benzoic acid protons or protons of benzoic acid derivative at $\delta=7.4-8.0 \mathrm{ppm}$ (Figure S6b). Quantitative analysis of the NMR spectrum revealed ratio of one benzoate group per 56 TMC units which correlates with initial amount of $\left[\mathrm{Zr}(\mathrm{acac})_{4}\right]$ and monomer (taking into account precipitation and partial removal of low-molar-mass fraction), thus, not correlating with molar mass evolution in MTC-COOH copolymerization.

\subsection{Hypothesized Mechanism of TMC ROP Initiation and} Polymerization Mediated with Zirconium Complex. Based on literature data and the results it is hypothesized that in the first step relatively dormant $\left[\mathrm{Zr}(\mathrm{acac})_{4}\right]$ (1) is doped with acidic proton originating from benzoic acid (2) molecule which leads to release of acetylacetone $(\mathrm{acacH}, 3)$ and in situ generation of coordinatively unsaturated heptavalent zirconium complex (4) (Scheme 2).

Release of acetylacetone affects also the Zr-complex geometry. Such generated zirconium complex possesses structure allowing coordination of oxacyclic monomers (5), analogously to the known LA or CL polymerization mechanism $[19,20]$. Next, the coordinated cyclic molecule undergoes ring-opening reaction and insertion between the metal and benzoate group (6). Break of the bond between zirconium atom and oxygen atom of benzoate is followed by creation of a new bond between zirconium atom and oxygen of TMC while another end of the opened monomer is hypothesized to form mixed carboxylic-carbonic anhydride. Subsequent repetition of the monomer insertion leads to polymeric molecule growth. The hypothesized mechanism explains linear macromolecules growth and end-capping of the polymer chain with benzoate derivative revealed in NMR and SEC experiments.

Discussing the polymerization mechanism further, in excess of carboxylic acid, one can imagine release of further acacH (3) molecules and further ligand exchange (7). It should allow growth of polymer chain from the zirconium atom in two and more directions. The process is not completely understood though gathered data suggest at least dominating, if not exclusive, growth of single polymeric chain per one molecule of zirconium complex which again correlates with previously described facts $[19,20]$. The most probably bond between zirconium atom and O-alkyl is the most vulnerable for cleavage and majority of insertion acts take place in single site of the initiator. Therefore, molar mass of the product in this experiment is determined by monomer/zirconium ratio and not by monomer/carboxylic acid ratio.

Drawing of the hypothesis on polymerization mechanism allows to speculate on molar mass discrepancy in MTC$\mathrm{COOH} / \mathrm{LA}$ copolymerization experiment (Table 1). Ability of $\left[\mathrm{Zr}(\mathrm{acac})_{4}\right]$ to exchange ligands as well as higher affinity of carboxylic acid than chelating acetylacetonate [31] gives a hint. Ratio of carboxylic acid to zirconium complex was 300:1 (Table 1.) in the case of MTC-COOH copolymerization. It is suspected that coordinated growing polymeric chain was replaced with "fresh" carboxylic acid leading to growth of a new polymeric chain. Based on this hypothesis it is expected that in polymerization carried out with content of carboxylic acid significantly exceeding content of zirconium complex molar mass of the product is no longer controlled by the complex/monomer ratio as a consequence of transition reaction, i.e., replacing of growing polymer chain ligand with "fresh" carboxylic acid.

Another not clear phenomenon in copolymerization of MTC-COOH with LA is formation of linear macromolecules. Polymeric chains should be terminated with cyclic carbonate which should be able to undergo ring-opening reaction leading to branched or cross-linked structures (if intermolecular transesterification is encountered). In this study, existence of branched structures was not confirmed. However, based on literature data, molecules with oxacyclic polymer ends theoretically able to undergo ring-opening were observed during investigation of LA polymerization mediated with $\left[\mathrm{Zr}(\mathrm{acac})_{4}\right]$ though existence of branched structures was not confirmed therein too [19]. For the time being it is hypothesized that either aliphatic anhydride (in case LA units is first inserted molecule) or mixed carboxylic-carbonic anhydride (in case MTC-COOH unit is first inserted molecule) do not undergo ring-opening reaction since macromolecular tail constitutes hindrance retarding approach of oxacyclic end of the growing macromolecule to the coordination centre.

Closer look into synthesized PTMC end-group fidelity revealed that the benzoic acid derivative in the purified PTMC is an ester and not a mixed carboxylic-carbonic anhydride as expected (Figure 3).

One should also remember that no mixed carboxyliccarbonic anhydride was evidenced by ESI-MS analysis of sample Table 1, Entry 1 (Figure S5). Apparently, the mixed carboxylic-carbonic anhydrides are relatively not stable groups which undergo thermal decomposition, mainly with decarboxylation constituting respective esters, as described by Windholz [32]. Moreover, decomposition temperatures of isolated mixed anhydrides start at $120^{\circ} \mathrm{C}$ while some of them decarboxylate in THF solution even at $25^{\circ} \mathrm{C}$ [32]. Therefore, it is reasonable to expect that 48 hours of heating at $120^{\circ} \mathrm{C}$ in anhydrous condition during polymerization experiment converted the terminal groups into esters. 


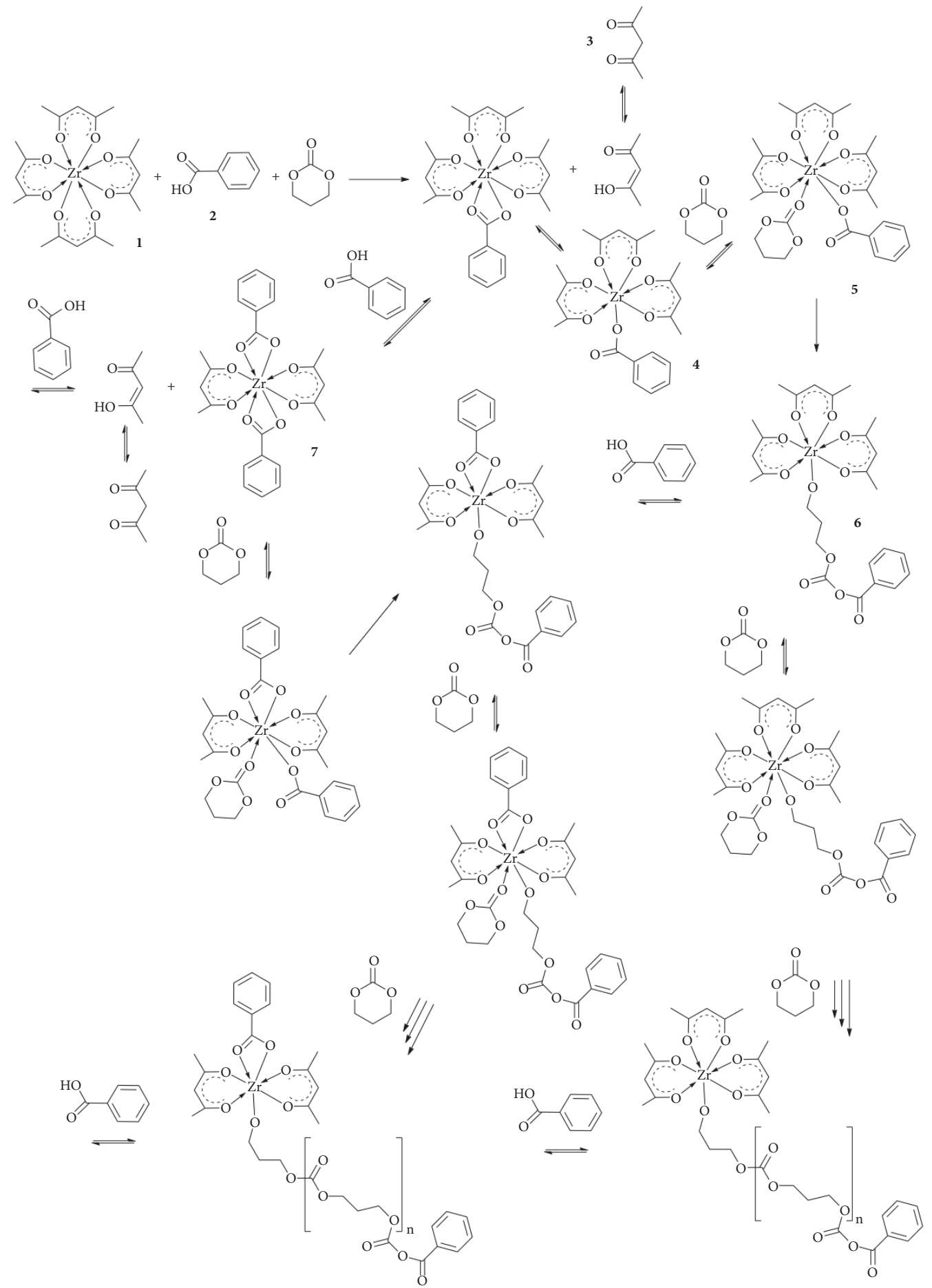

SCHEME 2: Hypothesized in situ catalyst generation and ROP mechanism of cyclic carbonate monomer mediated with $\left[\mathrm{Zr}(\text { acac })_{4}\right]$ precursor in presence of carboxylic acid.

3.4. Activity of the Zirconium Initiator. The finding was a driving force to carry out further experiments of MTC$\mathrm{COOH}$ copolymerization with LA in different monomer ratio (Table 2).
Repetition of the reaction at monomer ratio MTCCOOH/LA 30/70 carried out in reactor reducing LA sublimation resulted in copolymer comprising $31 \mathrm{~mol} \%$ of MTC$\mathrm{COOH}$ units. All resulting polymers revealed very good 


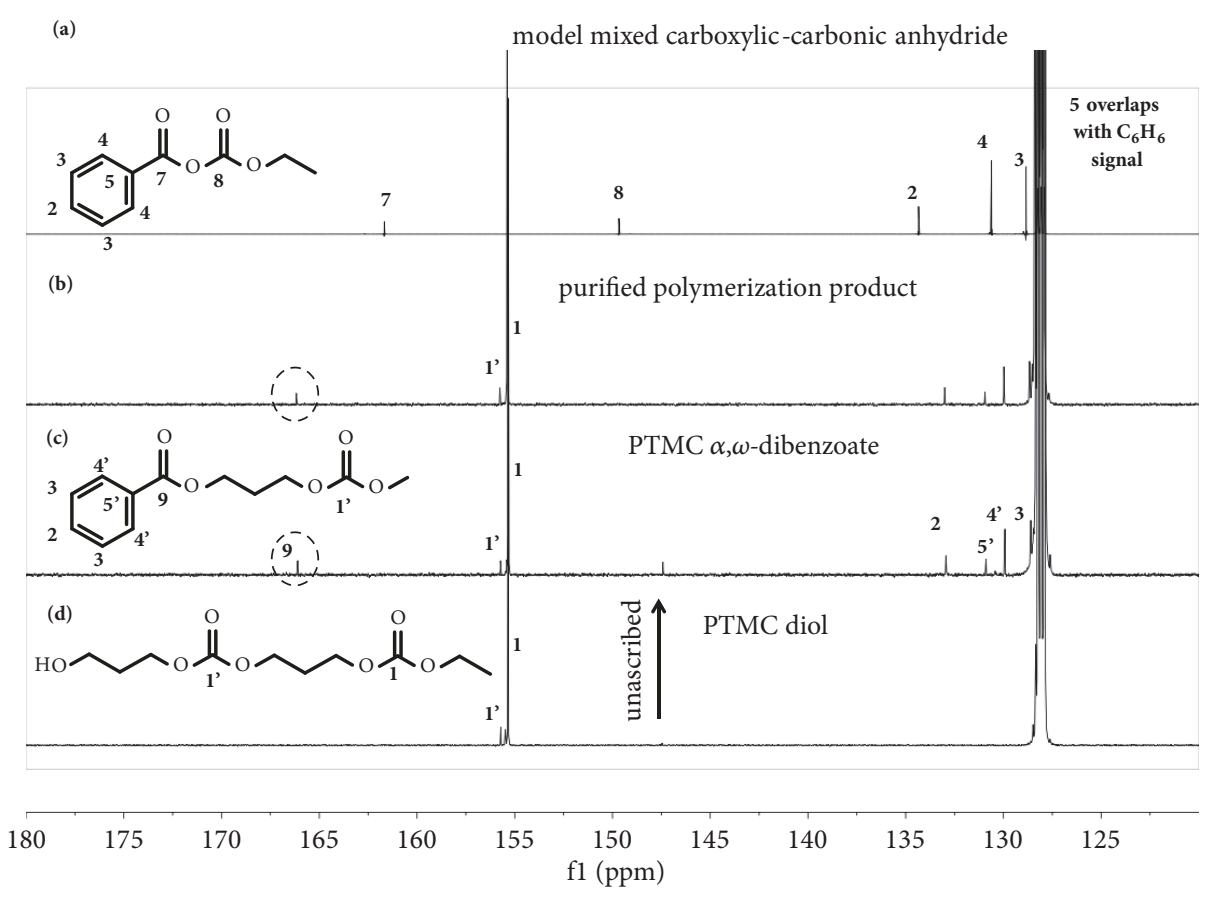

FIGURE 3: Overlaid ${ }^{13} \mathrm{C}$ NMR $\left(125 \mathrm{MHz}, \mathrm{C}_{6} \mathrm{D}_{6}\right)$ spectra in carbonyl carbon range $(\delta=180 \mathrm{ppm}-120 \mathrm{ppm})$ of (a) model mixed carboxyliccarbonic anhydride; (b) synthesized PTMC after purification; (c) benzoic acid ester of PTMC diol; and (d) PTMC diol.

correlation with expected composition. Apparently, reacting mixture with $70 \mathrm{~mol} \%$ content of MTC-COOH did not appear like homogenous substance. The problem is relatively high melting point of the carbonate monomer which is $c a$. $167^{\circ} \mathrm{C}$ (Figure S7) and its limited solubility in the melt during polymerization course. Nevertheless, even in this case total conversion yielded 95\%. Experiment of MTC-COOH bulk homopolymerization revealed lack of the melt in the reactor vessel at $130^{\circ} \mathrm{C}$. Loaded crystals mixed with $\left[\mathrm{Zr}(\mathrm{acac})_{4}\right]$ looked like sintered. Even though after $3 \mathrm{~h}$ of the reaction course monomer conversion yielded almost $40 \%$ (based on ${ }^{1} \mathrm{H}$ NMR, Figure S8).

\section{Conclusions}

Summing up it should be stated that alkane- and arenesoluble low toxic zirconium (IV) acetylacetonate constitutes precursor of effective catalyst active in ring-opening polymerization of cyclic esters and carbonates even in presence of carboxylic acids. In fact, generation of ROP-active zirconiumbased catalyst requires presence of Brønsted-Lowry acid which upon reaction with $\left[\mathrm{Zr}(\mathrm{acac})_{4}\right]$ and release of at least one acetylacetone molecule mediates polymerization of oxacyclic monomers. Peculiar feature of the zirconium catalyst makes it active in presence of $\mathrm{C}-\mathrm{H}$ acids (e.g., lactide, caprolactone, and glycolide) and carboxylic acids enabling ROP of cyclic esters and cyclic carbonates. Application of the $\left[\mathrm{Zr}(\mathrm{acac})_{4}\right]$ enables single-step polymerization of monomers with high conversion though the greatest advantage is preservation of intact carboxylic acid function. Thus, the catalysis gives access to brand new library of biodegradable polymers obtained in single step. Molar mass of the polymers is controlled by initiator/monomer ratio as long as content of carboxylic acid does not exceed coordination ability of the zirconium. Advantageously, low toxicity of the zirconium compounds combined with bulk process and high conversion of monomers generates the opportunity to apply such-obtained polyacids directly in biomedical field (for instance for nanostructures formulation or conjugation with drugs). One should also consider polymerization of oxacyclic monomers mediated with $\left[\mathrm{Zr}(\mathrm{acac})_{4}\right]$ in presence of carboxylic acid as a single-step end-capping method to obtain macromolecules functionalized with desired carboxylic acid or grafting-from procedure.

Ongoing research is carried out to resolve doubts on the hypothesized polymerization mechanism and the practical application of the discovery.

\section{Data Availability}

The data used to support the findings of this study are available from the corresponding author upon request.

\section{Conflicts of Interest}

The authors declare that there are no conflicts of interest regarding the publication of this paper. 


\section{Acknowledgments}

The work was performed within the framework of the Research Project no. 2012/07/B/ST5/00616 funded by the National Science Centre Poland.

\section{Supplementary Materials}

Supplementary Materials available: supporting figures. (Supplementary Materials)

\section{References}

[1] G. Rokicki, "Aliphatic cyclic carbonates and spiroorthocarbonates as monomers," Progress in Polymer Science, vol. 25, no. 2, pp. 259-342, 2000.

[2] S. Tempelaar, L. Mespouille, O. Coulembier, P. Dubois, and A. P. Dove, "Synthesis and post-polymerisation modifications of aliphatic poly(carbonate)s prepared by ring-opening polymerisation," Chemical Society Reviews, vol. 42, no. 3, pp. 1312-1336, 2013.

[3] L. Mespouille, O. Coulembier, M. Kawalec, A. P. Dove, and P. Dubois, "Implementation of metal-free ring-opening polymerization in the preparation of aliphatic polycarbonate materials," Progress in Polymer Science, vol. 39, no. 6, pp. 1144-1164, 2014.

[4] J. Feng, R. Zhuo, and X. Zhang, "Construction of functional aliphatic polycarbonates for biomedical applications," Progress in Polymer Science, vol. 37, no. 2, pp. 211-236, 2012.

[5] J. Xu, E. Feng, and J. Song, "Renaissance of aliphatic polycarbonates: new techniques and biomedical applications," Journal of Applied Polymer Science, vol. 131, no. 5, 2014.

[6] W. Chen, F. Meng, R. Cheng, C. Deng, J. Feijen, and Z. Zhong, "Advanced drug and gene delivery systems based on functional biodegradable polycarbonates and copolymers," Journal of Controlled Release, vol. 190, pp. 398-414, 2014.

[7] A. Frère, M. Kawalec, S. Tempelaar et al., "Impact of the structure of biocompatible aliphatic polycarbonates on sirna transfection ability," Biomacromolecules, vol. 16, no. 3, pp. 769779, 2015.

[8] Z. Y. Ong, K. Fukushima, D. J. Coady, Y.-Y. Yang, P. L. R. Ee, and J. L. Hedrick, "Rational design of biodegradable cationic polycarbonates for gene delivery," Journal of Controlled Release, vol. 152, no. 1, pp. 120-126, 2011.

[9] Y. Dai and X. Zhang, "Recent development of functional aliphatic polycarbonates for the construction of amphiphilic polymers," Polymer Chemistry, vol. 8, no. 48, pp. 7429-7437, 2017.

[10] S. H. Kim, J. P. K. Tan, K. Fukushima et al., "Thermoresponsive nanostructured polycarbonate block copolymers as biodegradable therapeutic delivery carriers," Biomaterials, vol. 32, no. 23, pp. 5505-5514, 2011.

[11] C. Yang, J. P. K. Tan, W. Cheng et al., "Supramolecular nanostructures designed for high cargo loading capacity and kinetic stability," Nano Today, vol. 5, no. 6, pp. 515-523, 2010.

[12] C. Bartolini, L. Mespouille, I. Verbruggen, R. Willem, and P. Dubois, "Guanidine-based polycarbonate hydrogels: from metal-free ring-opening polymerization to reversible selfassembling properties," Soft Matter, vol. 7, no. 20, pp. 9628-9637, 2011.
[13] M. Shi, J. Wosnick, K. Ho, A. Keating, and M. Shoichet, "Immuno-polymeric nanoparticles by diels-alder chemistry," Angewandte Chemie, vol. 119, no. 32, pp. 6238-6243, 2007.

[14] J. Lu and M. S. Shoichet, "Self-assembled polymeric nanoparticles of organocatalytic copolymerizated d, 1 -lactide and 2methyl 2-carboxytrimethylene carbonate," Macromolecules , vol. 43, no. 11, pp. 4943-4953, 2010.

[15] J. Jaworska, M. Kawalec, M. Pastusiak et al., "Biodegradable polycarbonates containing side carboxyl groups-synthesis, properties, and degradation study," Journal of Polymer Science Part A: Polymer Chemistry, vol. 55, no. 17, pp. 2756-2769, 2017.

[16] T. F. Al-Azemi and K. S. Bisht, "One-step synthesis of polycarbonates bearing pendant carboxyl groups by lipase-catalyzed ring-opening polymerization," Journal of Polymer Science Part A: Polymer Chemistry, vol. 40, no. 9, pp. 1267-1274, 2002.

[17] H.-F. Wang, H.-Z. Jia, J.-Y. Zhu et al., "One-step preparation and ph-tunable self-aggregation of amphoteric aliphatic polycarbonates bearing plenty of amine and carboxyl groups," Macromolecular Bioscience, vol. 12, no. 12, pp. 1689-1696, 2012.

[18] R. J. Lewis, Sax's Dangerous Properties of Industrial Materials, Van Nostrand Reinhold, New York, NY, USA, 1992.

[19] P. Dobrzynski, "Initiation Process of L-Lactide Polymerization Carried Out with Zirconium(IV) Acetylacetonate," Journal of Polymer Science Part A: Polymer Chemistry, vol. 42, no. 8, pp. 1886-1900, 2004.

[20] P. Dobrzynski, "Mechanism of $\varepsilon$-caprolactone polymerization and $\varepsilon$-caprolactone/trimethylene carbonate copolymerization carried out with $\mathrm{Zr}$ (Acac)4," Polymer Journal, vol. 48, no. 8, pp. 2263-2279, 2007.

[21] M. Bero, P. Dobrzyński, and J. Kasperczyk, "Application of zirconium (IV) acetylacetonate to the copolymerization of glycolide with $\varepsilon$-caprolactone and lactide," Polymer Bulletin, vol. 42, no. 2, pp. 131-139, 1999.

[22] P. Dobrzynski, J. Kasperczyk, H. Janeczek, and M. Bero, "Synthesis of biodegradable copolymers with the use of low toxic zirconium compounds. 1. Copolymerization of glycolide with L-lactide initiated by $\mathrm{Zr}$ (Acac)4," Macromolecules, vol. 34, no. 15, pp. 5090-5098, 2001.

[23] J. V. Silverton and J. L. Hoard, "Stereochemistry of discrete eight-coördination. Ii. the crystal and molecular structure of zirconium(IV) acetylacetonate," Inorganic Chemistry, vol. 2, no. 2, pp. 243-249, 1963.

[24] W. Clegg, "Redetermination of the structure of tetrakis(acetylacetonato)zirconium(IV)," Acta Crystallogr C, vol. 43, no. 4, pp. 789-791, 1987.

[25] Y. Chi, J.-W. Lan, W.-L. Ching, S.-M. Peng, and G.-H. Lee, "Syntheses and characterization of mixed acetylacetonatecatecholate complexes of zirconium, [Zr3(acac)4(cat)4(MeOH)2], $[\mathrm{Zr}(\mathrm{acac}) 2(\mathrm{DBcat})] 2(\mathrm{H} 2 \mathrm{DBcat}=3$, 5-di-terMmtylcatechol) and $[\mathrm{Zr} 4(\mathrm{u} 4-\mathrm{O})(\mathrm{acac}) 4(\mathrm{DBcat}) 3(\mathrm{OMe}) 4(\mathrm{MeOH})]$," Journal of the Chemical Society, Dalton Transactions, no. 17, pp. 2923-2927, 2000.

[26] F. Nederberg, V. Trang, R. C. Pratt et al., "New ground for organic catalysis: a ring-opening polymerization approach to hydrogels," Biomacromolecules, vol. 8, no. 11, pp. 3294-3297, 2007.

[27] R. C. Pratt, F. Nederberg, R. M. Waymouth, and J. L. Hedrick, "Tagging alcohols with cyclic carbonate: a versatile equivalent of (meth)acrylate for ring-opening polymerization," Chemical Communications, no. 1, pp. 114-116, 2008.

[28] A. Smola, P. Dobrzynski, M. Cristea et al., "Bioresorbable terpolymers based on 1-lactide, glycolide and trimethylene 
carbonate with shape memory behaviour," Polymer Chemistry, vol. 5, no. 7, pp. 2442-2452, 2014.

[29] W.-S. Jung, H. Ishizaki, and H. Tomiyasu, "Kinetics and mechanism of ligand exchange in tetrakis(acetylacetonato)zirconium(IV) in organic solvents," Journal of the Chemical Society, Dalton Transactions, no. 7, pp. 1077-1081, 1995.

[30] P. Dobrzynski, M. Pastusiak, and M. Bero, "Less toxic acetylacetonates as initiators of trimethylene carbonate and 2,2dimethyltrimethylene carbonate ring opening polymerization," Journal of Polymer Science Part A: Polymer Chemistry, vol. 43, no. 9, pp. 1913-1922, 2005.

[31] A. Suzuki, A. Mochizuki, N. Minamide, S. Natzume, H. Shirai, and N. Hojo, "Mechanism of the transesterification of methyl benzoate with ethylene glycol catalyzed by metal acetylacetonates complexes," Nippon Kagaku Kaishi, vol. 1976, no. 6, pp. 983-987, 1976.

[32] T. B. Windholz, "Decomposition of mixed carboxylic-carbonic anhydrides," The Journal of Organic Chemistry, vol. 25, no. 10, pp. 1703-1707, 1960. 


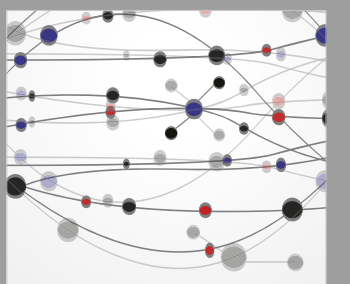

The Scientific World Journal
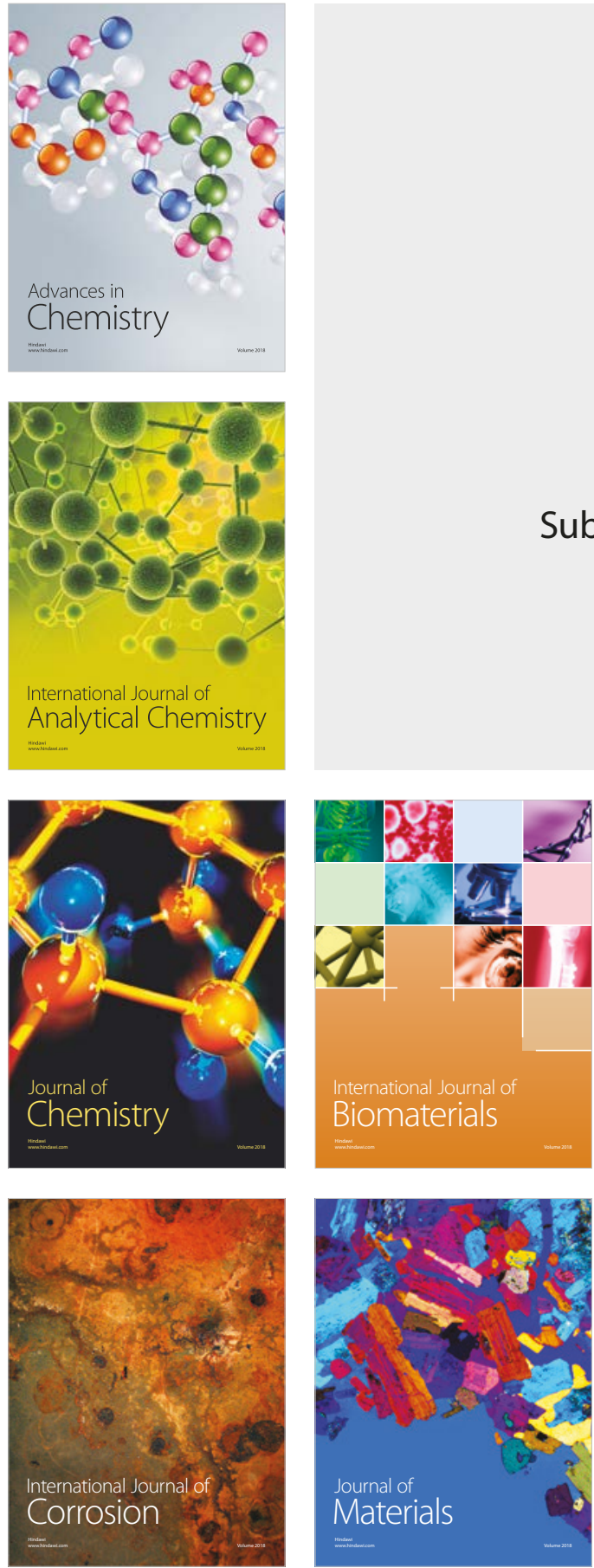

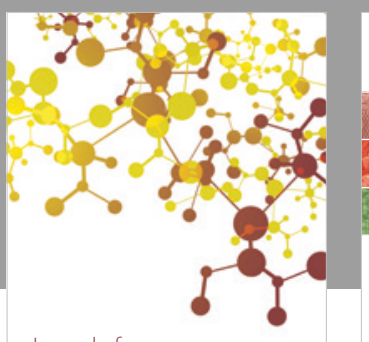

Journal of

Applied Chemistry
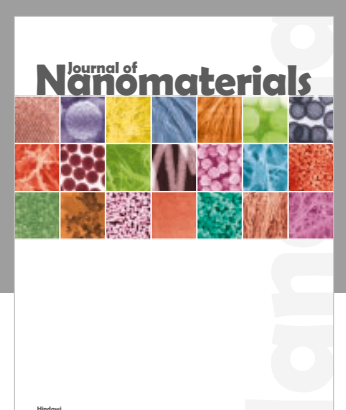

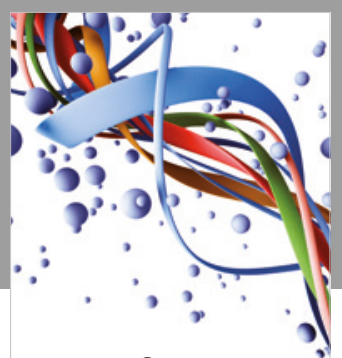

Scientifica

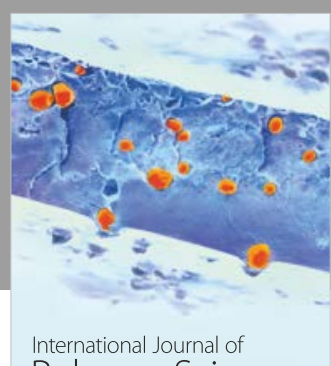

Polymer Science

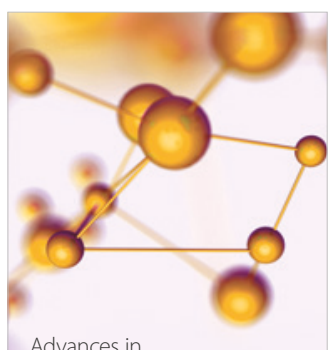

Physical Chemistry
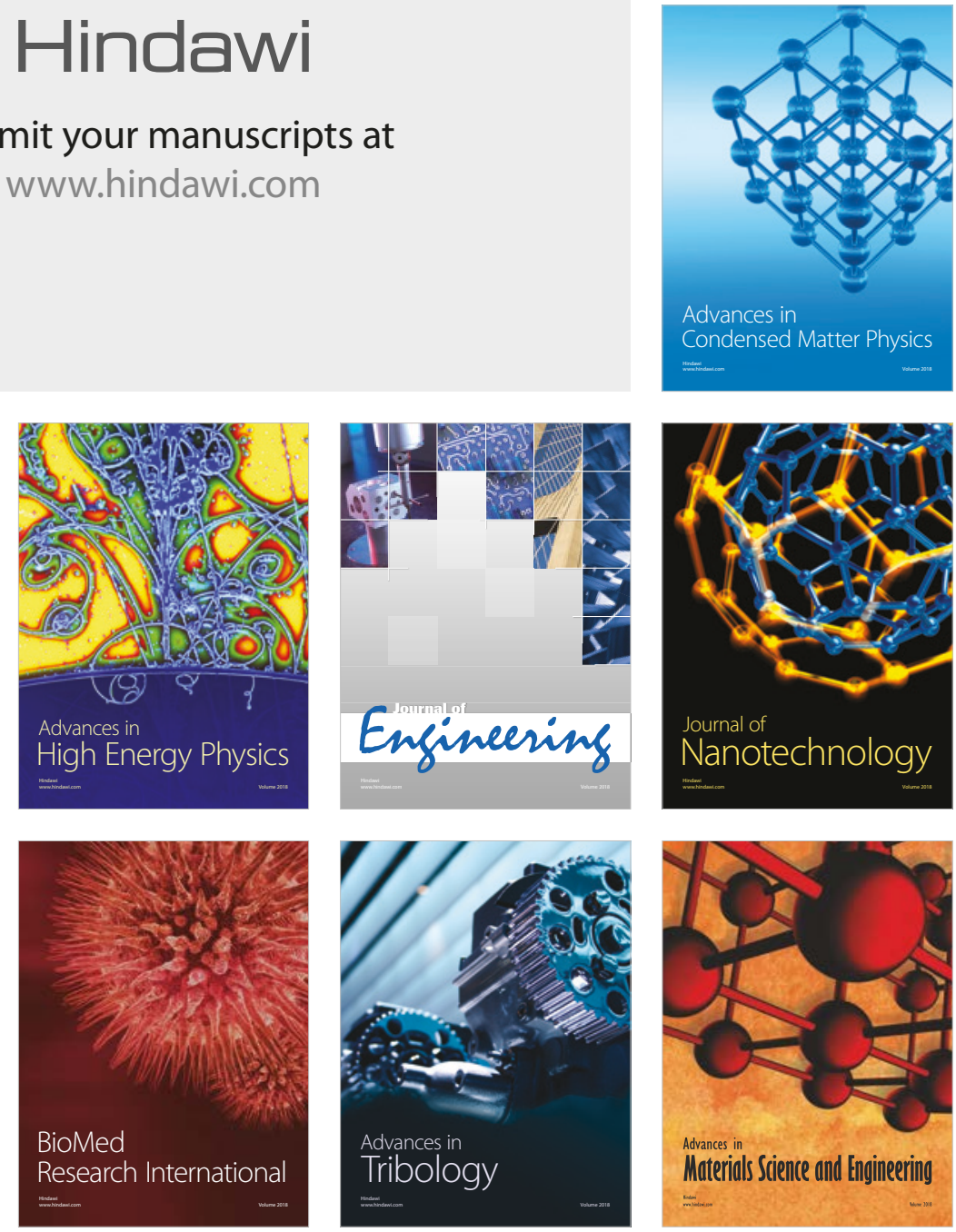